\title{
Martyrs for Free Speech? Disentangling the Effects of Legal Prosecution of Anti-immigration Politicians on their Electoral Support
}

\author{
Laura Jacobs $^{1} \cdot$ Joost van Spanje ${ }^{1}$
}

Published online: 5 November 2019

(c) The Author(s) 2019

\begin{abstract}
Several anti-immigration politicians in Europe have been prosecuted for hate speech; some of these trials were highly mediatized. To what extent, and how, does hate speech prosecution of anti-immigration politicians affect voting for their party? We address this question by an experiment $(\mathrm{N}=372)$ using manipulated versions of a television news story about a politician of the Dutch Party Forum for Democracy $(\mathrm{FvD})$. We go beyond prior studies by disentangling the mechanisms driving the electoral ramifications of hate speech prosecution, assessing the moderating role of multiculturalist attitudes separately and in combination with six mediators (antiestablishment attitudes, issue salience immigration, perceived party's effectiveness and legitimacy, support for free speech, and perceived party visibility). Among voters who are positive toward multiculturalism, exposure to a news story about prosecution boosts support for free speech and perceived visibility and support for the FvD. Both aspects are positively related to voting for FvD. This improves our understanding of the mechanisms of hate speech prosecution, informing public debates of how to react to controversial speech by politicians.
\end{abstract}

Keywords Experiment $\cdot$ News $\cdot$ Anti-immigration party $\cdot$ Hate speech $\cdot$ Voting behavior $\cdot$ FvD $\cdot$ Freedom of speech

Electronic supplementary material The online version of this article (https://doi.org/10.1007/s 1110 9-019-09581-6) contains supplementary material, which is available to authorized users.

Laura Jacobs

1.c.n.jacobs@uva.nl

Joost van Spanje

J.H.P.vanSpanje@uva.nl

1 Department of Communication, Amsterdam School of Communication Research (ASCoR), University of Amsterdam, Nieuwe Achtergracht 166, 1018 WV Amsterdam, Noord-Holland, The Netherlands 


\section{Introduction}

Today, in multiple European societies anti-immigration parties ${ }^{1}$ are thriving. Generally speaking, these types of parties have performed well during elections (Stockemer 2017). The popularity of these parties has sparked controversy due to the rhetoric that is often used by their representatives and leaders, in which immigrants and other ethnic, and/or religious minorities have been targeted. Following their discourse, several anti-immigration party leaders in Europe have been accused of inciting racial hatred, and legal actions against these politicians have been initiated by country authorities (Van Donselaar 1995; Vrielink 2010). In several cases, these trials have culminated in the conviction of the prosecuted party leader for hate speech (Fennema 2000). High-profile cases include Geert Wilders (leader of the Dutch PVV), Jean-Marie Le Pen (former leader of the French RN) and Gunther Deckert and Udo Voigt (both former leaders of the German NPD).

These cases have led some political scientists to wonder about the electoral ramifications of trials for alleged hate speech. This research is grounded in the supposition that legal actions against anti-immigration party leaders may offer an additional explanation, next to classical voting behavior theories, in clarifying why some antiimmigration parties have been more successful at the ballot box than others (Van Spanje and De Vreese 2015). The prosecution of politicians for inciting racial hatred may be a contextual-level factor affecting the electoral performance of anti-immigration parties. So far, however, only a handful of studies have empirically investigated the electoral ramifications of the prosecution of an anti-immigration party leader for hate speech (Jacobs and van Spanje 2018). Apart from no effect, two outcomes are possible: legal actions against anti-immigration politicians can either be an effective device to erode anti-immigration parties' support, or prosecution may benefit these parties' electoral success (Van Spanje and De Vreese 2015). A recent study has found that in the Dutch context the prosecution of Party for Freedom (PVV) leader Wilders in 2011 has contributed to an electoral lift-off (Van Spanje and De Vreese 2015). This finding was, however, conditional upon specific voter traits: a positive effect of prosecution on electoral support was found particularly for voters with a critical stance toward multicultural society. One thus needs to consider moderating factors, i.e. multicultural attitudes, when assessing electoral effects of hate speech prosecution. In this study, we draw upon this finding and study how exactly the legal prosecution of anti-immigration politicians affects levels of electoral support.

We tackle this question via testing a set of explanations (i.e., mediators) that may underlie this effect. We draw on the rich body of literature about electoral behavior as our point of departure. Studies assessing the electoral strength of anti-immigration parties underline the pivotal role of individual-level voter traits and perceived party characteristics as core determinants of electoral behavior. Learning about a decision to legally prosecute an anti-immigration party leader for inciting racial

\footnotetext{
1 We refer to anti-immigration parties as a specific category of political parties that primarily mobilize on the immigration issue (Fennema 1997; Van Spanje 2011). These are characterized by opposition against immigration, favoring stricter policies.
} 
hatred may affect voters' attitudes or perceptions of these parties, which may, in turn, influence their electoral behavior (Bos and Van der Brug 2010). Building on this insight, we aim to contribute to the literature about the effects of hate speech prosecution on anti-immigration party support via offering an empirical test of the underlying mechanisms that may be at play. To the best of our knowledge, this is the first study to do so systematically. We define hate speech as 'all forms of expression which spread, incite, promote or justify hatred based on intolerance' (Weber 2009, p. 3). We design an experiment in which participants are exposed to one of several manipulated versions of a television news story on the prosecution of a politician of the Dutch Forum for Democracy (FvD) for hate speech. Hence, we focus on a specific type of hate speech, namely hate speech by elected officials; the consequences of this type of trial are likely to be far-reaching and thereby relevant to study. Six explanations or mediators based on voting behavior literature are assessed. In this way, providing evidence from the Dutch context, we aim to help clarify the electoral ramifications of hate speech prosecution, and shed more light on the underlying mechanism. This study should be seen as a first step in evaluating the implications of hate speech prosecution for anti-immigration parties' electoral viability, providing an indication of whether such prosecution has the unintended effect of mobilizing electoral support for the defendant's party.

\section{Theoretical Framework}

\section{The electoral Ramifications of Hate Speech Prosecution}

In recent decades, several anti-immigration politicians have been prosecuted for inciting racial hatred. These acts of legal prosecution could be a novel, partial explanation for the varying electoral performance of anti-immigration parties in Europe (Van Spanje and De Vreese 2015). Legal action against anti-immigration politicians is usually justified as a necessary instrument to restrict violations of the anti-racism law, directed at preserving core democratic values in liberal societies (Van Donselaar 1995). This relates to conceptions of societies as militant democracies, the idea that democracies should be entitled to defend themselves from threats to their democratic nature (Capoccia 2013; Loewenstein 1937; Minkenberg 2006; Thiel 2009). While aimed at neutralizing threats to democratic and liberal principles, such as the equality principle, legal actions against politicians can have unintended ramifications (Van Donselaar 1995). Some scholars have referred to this as a paradox, implying that acts of legal prosecution of political leaders may backfire and translate into more political power for the prosecuted actors (Friedman 1970; Kirchheimer 1961).

To date, only a handful of studies has closely investigated the effects of hate speech prosecution, which can be considered as a type of legal control (Barkan 2006), on the viability of anti-immigration political actors. There are several reasons why hate speech prosecution may benefit anti-immigration party support (Van Spanje and De Vreese 2015). The prosecution could grant the politician free publicity in the news media which could increase its electoral appeal; it may reinforce the association between the prosecuted politician and the issue that (s)he is prosecuted 
for. Statements about immigration or multiculturalism, which usually are the reason for hate speech prosecution, may receive more attention and this emphasis could actually benefit anti-immigration parties as they 'own' these issues. Finally, prosecution could also provide these politicians with an opportunity to present them as martyrs for free speech. The findings regarding the electoral effects of hate speech prosecution are, however, mixed. A study by Capoccia (2005) has concluded that under certain circumstances legal action against political actors can erode their electoral support bases. Still, a recent empirical study in the Dutch context has found that legal prosecution of Party for Freedom (PVV) leader Wilders has boosted PVV support (Van Spanje and De Vreese 2015). The electoral effects of hate speech prosecution have, however, also been found to depend on voter traits. The positive effect on PVV party support was found to be especially strong for voters with a moderate assimilationist attitude. Hate speech trials give rise to debates referring to the delicate balancing act between allowing criticism of multiculturalism on the one hand and the protection of minority rights via curbing racist speech on the other hand. Therefore, prosecution is likely to trigger a wave of electoral support especially amongst voters who agree with the ideas of a politician who has been prosecuted for hate speech (Van Spanje and De Vreese 2015). We therefore hypothesize:

$\mathrm{H}_{1}$ Exposure to a news story about the hate speech prosecution of an anti-immigration politician has a positive effect on anti-immigration party support amongst voters who oppose multiculturalism.

\section{Disentangling the Mechanism}

\section{Priming Theory}

A first explanation can be found in priming theory (Sheafer 2007). The prosecution of a politician is likely to be considered newsworthy by journalists since it meets a set of informal news values, such as conflict and an elite-focus (Harcup and O'Neill 2017). When an anti-immigration politician is tried for disseminating hate speech messages, the trial will likely be mediatized, boosting the visibility of both the party and its leader in the public sphere. Prior research has compellingly demonstrated a positive relationship between leaders' and parties' news visibility and their electoral success (e.g., in terms of preferential votes) (Van Aelst et al. 2008). This has been verified specifically for anti-immigration parties too (Vliegenthart et al. 2012). Especially in recent times where electoral volatility is on the rise, news can guide voting behavior. This has a priming aspect, because it entails voters to perceive a party as salient due to news coverage about hate speech prosecution. The priming occurs if voters next apply this easily accessible information when evaluating this party (Scheufele and Tewksbury 2007). We hypothesize that:

$\mathbf{H}_{2}$ The relationship between exposure to a news story about the legal prosecution of an anti-immigration politician for hate speech and anti-immigration party support is mediated by the visibility of that anti-immigration party. 


\section{Issue Ownership Theory}

Issue ownership theory asserts that parties are perceived by the public to have expertise to handle specific political issues, that is that they are perceived as the 'owner' of an issue (Petrocik 1996; Van der Brug 2004). Issue ownership has been recognized as a strategy for political parties to solidify their electoral success (Bélanger and Meguid 2008; Green and Hobolt 2008). Issue ownership entails two dimensions: a 'competence' and an 'associative' dimension (Walgrave et al. 2012). The former dimension relates to voters' perceptions that a political party is qualified to deal with a policy issue, while the latter refers to the spontaneous connection that voters make between a party and a given policy issue. Especially this associative dimension is of importance to our argument. In several contexts, anti-immigration parties are perceived by the electorate as most prominent owners of the immigration issue (Burscher et al. 2015; Damstra et al. in press; Walgrave and De Swert 2004). This implies that these parties are likely to electorally benefit if the media and political debate focus on their preferred issues (Bos et al. 2017), granting these parties an incentive to keep the immigration issue high on the political agenda. The salience of the immigration issue is positively linked to anti-immigration party support. Legal action against an anti-immigration politician for racial hatred is usually preceded by statements in which immigrant or ethnic, racial and/or religious minority groups are targeted (Vrielink 2010). Hate speech prosecution of an anti-immigration politician may prompt discussions about criticism of multiculturalism, immigration and the integration of ethnic minorities. Hence, news about the prosecution of an anti-immigration politician for hate speech may make the ethnic diversity and immigration issue more salient which, following issue ownership theory, should result in rising electoral support for anti-immigration parties. We hypothesize that:

$\mathbf{H}_{3}$ The relationship between exposure to a news story about the legal prosecution of an anti-immigration politician for hate speech and anti-immigration party support is mediated by perceived issue salience of immigration.

\section{Perceived Party Effectiveness}

Support for anti-immigration parties has been found to be partly determined by their level of perceived effectiveness (Bos and Van der Brug 2010). This concept originates from rational choice theory (Downs 1957) proclaiming that many voters cast a vote based on rational considerations. Those voters, in this viewpoint, hold a preference for a party due to the anticipated outcome of the policy or specific agenda this party will strive for. A party's perceived effectiveness refers to perceptions by the electorate that a given party or leader is in a position to meet political demands. Viability and the perception of being able to deliver policy output is, hence, vital to any party. This applies to anti-immigration parties as well: voters expect them to deliver their promise via initiating change in terms of immigration policy, or via at least weighing on the immigration debate (Van der Brug et al. 2005). Antiimmigration actors, hence, need to cultivate a public image as effective and relevant political actors, even from the opposition benches. One of the available strategies for 
parties to enhance their perceived effectiveness is ensuring their presence in political debates, and exerting influence on the media and the political agenda (Bos and Van der Brug 2010). News visibility of a party is a fruitful instrument to increase parties' perceived effectiveness (Bos and Van der Brug 2010; Hopmann et al. 2010). The prosecution of a party leader for hate speech, in particular, is likely to generate extensive attention, granting that politician a public forum to address a large audience. This may lead voters to believe that this politician occupies a key position as a high-level actor in the political arena. Coverage of the prosecution of an anti-immigration party leader may boost this party's perceived effectiveness, which in turn could benefit electoral support for these parties. ${ }^{2}$ We hypothesize that:

$\mathbf{H}_{4}$ The relationship between exposure to a news story about hate speech prosecution and anti-immigration party support is mediated by the party's perceived effectiveness.

\section{Perceived Legitimacy}

Perceived legitimacy refers to voters' expectations that a party operates within the boundaries of the democratic system, and its behavior is not at odds with core democratic principles (Berntzen et al. 2017; Carter 2005); it is a fundamental party feature, which has been validated to-at least partially-affect electoral behavior (Bos and Van der Brug 2010; Eatwell 2003). Prosecution of an anti-immigration politician for hate speech can be a reason for delegitimation of that party for at least three reasons. First, an anti-racism norm has been said to prevail in Western democracies, which may partially explain why some anti-immigration parties fail (Blinder et al. 2013). The reasoning is that a deeply-rooted social norm within democratic societies exists, rendering blatant expressions of prejudice socially intolerable (Mendelberg 2001; Pettigrew and Meertens 1995). If a party is perceived not to respect these fundamental principles, e.g. via targeting minorities and being prosecuted for it, this may have a bearing on that party's level of perceived legitimacy. Second, prosecution may bring along stigmatization: in the Netherlands, recent studies have found that stigmatizing the PVV via linking them to extremist ideologies as neo-Nazism and fascism de-legitimatized the PVV, decreasing their electoral support (Van Heerden and Van der Brug 2017; Van Spanje and Azrout 2019). Third, knowledge that a politician has come into contact with the legal system or has been 'criminalized' - even while they agree with the politician and the party — can be a step too far for some voters and in itself diminish levels of electoral support. It is

\footnotetext{
${ }^{2}$ While the opposite theoretical argument could be made (i.e., prosecution resulting in a lower perceived effectiveness, negatively impacting anti-immigration party support), this scenario is unlikely in the Dutch political context. First, as stressed by Van Spanje and De Vreese (2015), hate speech prosecution on itself does not imply conviction (which may have more negative connotations). Second, in the Netherlands severe punishments that could jeopardize a party's organization and stability, such as jailing a politician or stripping him of his political rights, are not possible in the case of hate speech prosecution. Hence, a scenario in which party's perceived effectiveness increases among voters seems far more likely than the opposite scenario.
} 
plausible to argue that exposure to a news story regarding hate speech prosecution yields similar mechanisms and decreases anti-immigration party support through reduced legitimacy.

$\mathbf{H}_{5}$ The relationship between exposure to a news story about hate speech prosecution and anti-immigration party support is mediated by the party's perceived legitimacy.

\section{Anti-establishment Attitudes}

Voters who sympathize with anti-immigration parties are, amongst other reasons, often charmed by the clear-cut anti-establishment profile of these parties (Cutts et al. 2011). Voters for anti-immigration parties are characterized by high levels of political cynicism, distrust and dissatisfaction (Kitschelt and McGann 1995); playing the anti-establishment card typically benefits anti-immigration actors (Cutts et al. 2011; Jagers and Walgrave 2007; Rooduijn et al. 2016). The prosecution of anti-immigration politicians resonates well with this anti-establishment rhetoric, as for some voters it may reinforce the idea already implanted in their minds that the political elite is corrupted. An often-voiced critique of trials against political actors is that they can be an instrument in the hands of political elites to discredit their political adversaries (Minkenberg 2006; More 1994). Claims that the legal prosecution of an antiimmigration politician is political in nature are quickly made (Belknap 1994; Friedman 1970; Hakman 1972; Kirchheimer 1961; Posner 2014). Political trials may have unintended effects, actually serving the defendant's goals. News coverage of a hate speech trial can be interpreted by some voters as a well-orchestrated attempt of the executive, legislative and judicial elite within a political system to silence their political rivals. The political cynicism and alienation of anti-immigration voters may make them susceptible to this interpretation. This may further advance these voters' aversion of the political establishment, which may translate in enhanced electoral support for anti-immigration parties:

$\mathbf{H}_{6}$ The relationship between exposure to a news story about the prosecution of an anti-immigration politician and anti-immigration party support is mediated by antiestablishment attitudes.

\section{Support for Freedom of Speech}

Politicians of European anti-immigration parties assert to defend free speech (Akkerman 2005). They portray themselves as the only party truly representing the ordinary people by voicing their concerns without considerations about political correctness. Prosecution of politicians for hate speech can be criticized from the angle of free speech, which is protected in domestic and international legislation as a core democratic right (Weber 2009). The narrow line between hate speech and free speech is a hotly debated topic; finding a balance between freedom of speech and protection of minority rights presents a core challenge for multicultural societies in Europe (Bleich 2011; Vrielink 2016). Defenders of free speech interpret it as an 

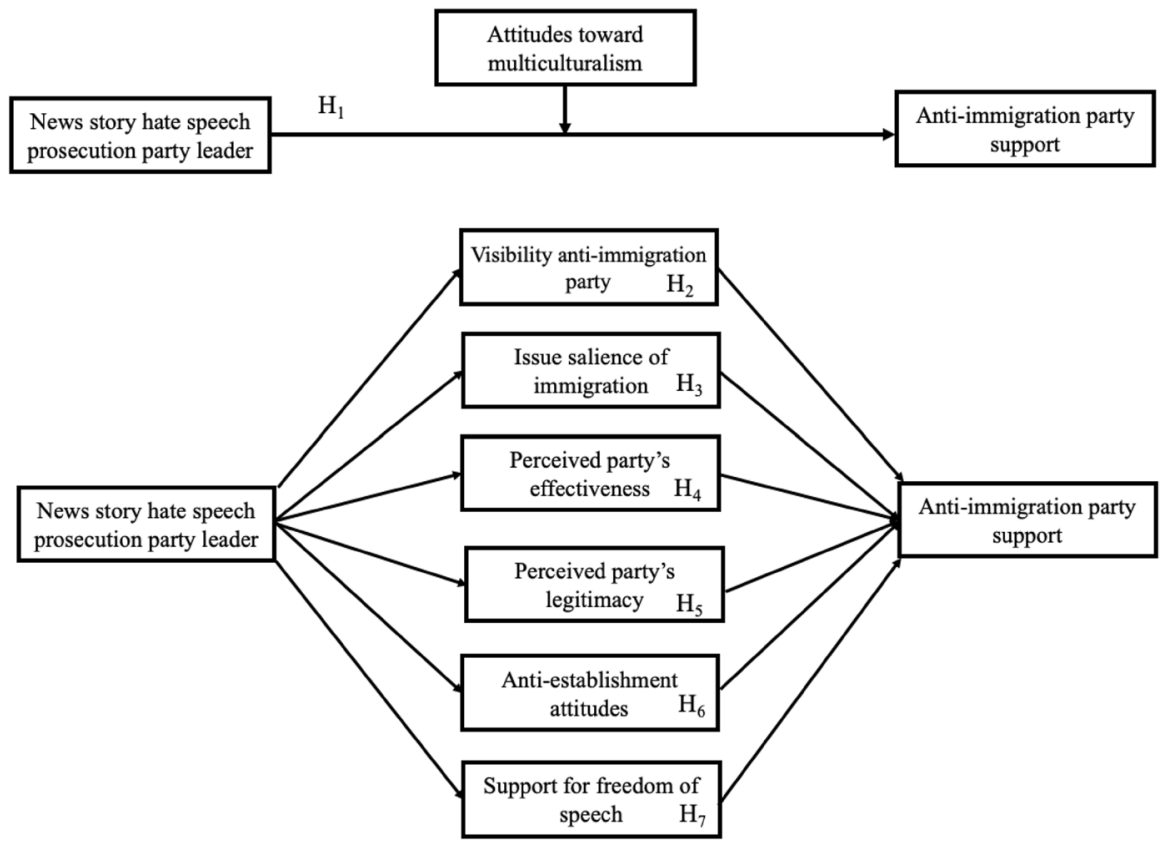

Fig. 1 Visual illustration of theoretical expectations

absolute right, implying that nobody-let alone a politician-should be punished for expressing his or her political ideas. Making an appeal to the free speech principle seems to attenuate people's disapproval of hate speech (Lahav and Courtemanche 2012). This grants politicians who are prosecuted for hate speech an incentive to portray themselves as victims or 'martyrs for freedom of speech' (Van Donselaar 1995). This is exactly what Wilders, PVV leader, did when he was prosecuted (Akkerman 2011) and after the decision to prosecute him in 2009 support for PVV increased (Van Spanje and De Vreese 2015). We expect that:

$\mathrm{H}_{7}$ The relationship between exposure to a news story about the prosecution of an anti-immigration party leader for hate speech and anti-immigration party support is mediated by support for freedom of speech.

The theoretical expectations are visualized in Fig. 1.

\section{Context: The Netherlands and the Forum for Democracy (FvD)}

In the experiment, participants were presented a television news story about the prosecution of an anti-immigration party leader for hate speech directed at Muslims. We opted for Muslims because they are the largest outgroup in the Netherlands, and they are most heavily targeted. More in particular, the participants watched a 
television news story about the Dutch anti-immigration party 'Forum for Democracy' (FvD), which is led by Thierry Baudet.

There are multiple reasons for why we opted for FvD. In order to successfully manipulate the news story, we needed an existing party (as it is uncertain how voters would respond to fictional parties, amongst others because they may project what they know about existing parties onto this fictional party), that is relevant and of which a member's hate speech prosecution seems realistic. It was also necessary to opt for a relatively new party, of which voters had not yet developed a clear image. For instance, picking PVV instead could introduce problems, because its leader had already been prosecuted twice.

For all these reasons, we opted for FvD. This party first participated in Dutch Parliamentary Elections in March 2017. Currently, FvD holds two seats in the Second Chamber: one seat is reserved for party leader and founder Baudet and the other seat for Theo Hiddema. The latter is a criminal lawyer who has gained a reputation following the handling of several high-profile lawsuits and controversial public remarks. For the experiment, we manipulate a news story about Hiddema. Party leader Baudet is a highly visible politician, which would make it more difficult to manipulate a news story. Hiddema is a better option, because he is a relevant FvD politician (although somewhat less prominent than Baudet), and his common provocative behavior makes it credible that he has made controversial statements. Finally, a focus on FvD as our case for hate speech prosecution is also credible from the viewpoint of what this party strives and stands for. It mobilizes on issues that are typically owned by anti-immigration parties. They have presented themselves as advocates of a restrictive immigration policy. Likewise, regarding Muslims, they perceive the arrival of (Islamic) immigrants as a threat to Dutch identity and the preservation of Dutch culture and traditions.

\section{Data and Method}

\section{Participants and Design}

We have conducted a web experiment with a between-subjects design. ${ }^{3}$ An experimental approach has a set of advantages. Most notably, it allows to substantiate causal claims. Participants were randomly allocated to either an experimental condition or a control condition in a controlled setting where only the former were exposed to an experimental stimulus, making that-if the randomization was successful-changes in the outcome can only be due to the stimulus. This allows us to keep confounding influences constant.

\footnotetext{
3 This web experiment was specifically designed for our research purposes, but it should be noted that the original experiment also included additional experimental conditions that are not relevant for the current study, resulting in a total $\mathrm{N}$ of 984 . In this study, however, we only used two conditions, leading to $\mathrm{N}=372$.
} 
In total, 372 participants took part in the online experiment ${ }^{4}$ (188 women, 184 men; $M_{\text {Age }}=52.2, \mathrm{SD}_{\mathrm{Age}}=17.5$. Thirty-seven per cent had a higher education degree). The data collection was done in cooperation with Kantar Public, and the experiment was fielded between June 25 and July 10, 2018. A representative sample of the Dutch population in terms of age, gender, education, area of residence, socioeconomic status and voting behavior was drawn. They were randomly allocated to either an experimental $(\mathrm{N}=181)$ or a control condition $(\mathrm{N}=191)$.

The experimental condition consisted of a television news story about Theo Hiddema. There was mentioning of hate speech by Hiddema and it was said that he would be prosecuted for it. In the control condition, the news story was identical, except that now the manipulation (i.e., decision to prosecute) was left out. ${ }^{5}$

\section{Procedure}

The experiment was conducted online. All participants received an e-mail with a link to the experiment in Qualtrics. To mask the objective of our study, we used a cover story. ${ }^{6}$ Participants were told that they would take part in a study about reactions to news on current affairs. ${ }^{7}$ After this introduction, they were presented a manipulated news episode of 'NOS Journaal in 60 seconds', a real program produced by the Dutch public broadcaster NPO. The program is broadcast three times a day, and it attracts a large audience. 'NOS Journaal in 60 seconds' is also released online on the NOS website and its social media channels. We made use of high-quality footage that has actually been disseminated on the news in the past, which was directed at enhancing external validity. The created situation in which the participants watch an online news story closely matches actual media habits in the Netherlands where news is increasingly consumed online. 'NOS Journaal in 60 seconds' is a 1-min newscast that reports on four issues per episode. Our manipulation made use of three news stories that were in reality disseminated as part of 'NOS Journaal in $60 \mathrm{sec}-$ onds' and one news story (on Hiddema) that we edited. This makes that the lay-out and format is nearly identical to that of the real program. All audio-visual content was kept constant across conditions, except for the manipulation, which consisted of a single sentence. The remaining three news stories were not manipulated, and we included variation in the topics that were addressed. They dealt with the average life expectancy in the Netherlands, the success rate of educational choices by students, and the declining popularity of sports and physical exercise amongst adolescents. These news stories were selected due to their societal relevance and relative neutrality so as to avoid priming participants with contentious policy issues. An additional

\footnotetext{
4 The dataset and replication code can be found at this link: https://doi.org/10.7910/DVN/Q7USJQ.

5 We had also had two other control conditions (a news story about an unrelated news topic, and a news story about Hiddema but with statements regarding another issue); we opted for the control condition with hate speech without info on prosecution as this is the best comparison. Generally, results are the same when comparing to these control conditions. Still, we see that comparing against these conditions, the salience of immigration is slightly higher, as expected.

6 When asked, none of the participants correctly guessed that we assessed the goal of the study.

7 The experiment was approved by the Ethical Committee of our University.
} 
reason for the selection of these particular news stories was that they were free of temporal cues and did not contain references to single events. All respondents were debriefed right after having taken the survey.

\section{Stimulus Materials}

The experimental conditions showed footage of Hiddema: in one shot, he is depicted preparing for a speech on a FvD national congress, in another shot he is shown strolling around in the Dutch National Parliament in the company of news reporter, and in the final shot he walks away from the pulpit in the parliament after having asked a question. The news story in the experimental manipulation condition was edited with a voice-over; this voice-over was recorded in a soundproof, professional editing studio by a professional. This voice-over only slightly differs between the experimental conditions. The voice-over mentions in the control condition that Hiddema has made public statements about Muslims. ${ }^{8}$ The experimental condition is identical, except that information is added that the Public Prosecutor has decided to prosecute him for these remarks. Online Appendices A1 and A2 offer a transcript and example (still images) of the manipulated news story.

After the manipulation, the participants answered buffer items, followed by questions about the dependent variables and mediators. These buffer items were presented to follow-up on the cover story and they dealt with the other policy issues in the manipulated newscast. We also included a manipulation check to ascertain that the manipulation was successful. In a final question, participants were asked about their guess of study's purpose.

\section{Measurements}

\section{DV: Propensity to Vote (PTV) for Forum for Democracy (FvD)}

Participants were asked to rate several political parties in the Dutch party system via the following question: "Could you indicate what the chances are that you will ever vote for each of the following party in the future. If you think that you will never vote for this party, please fill in ' 1 '. If it is very likely that you will once vote for this party, please fill in '10'. You can of course also choose any number in between." This was followed by a list of all Dutch parties that were represented in the Second Chamber at the time of data collection. To construct the variable 'PTV FvD', we employed the participants' ratings for $\operatorname{FvD}(M=3.01, S D=2.60)$. We also asked the question of which party respondents would vote for if the next day elections for the Second Chamber were held, offering them a close-ended list of Dutch parties

\footnotetext{
8 We deliberately opted to withhold additional information regarding the specific statement about Muslims, because what each respondent would find acceptable may differ. By leaving out additional information about the statement, we suggest that the statement was controversial enough for triggering debates about potential prosecution. In this way, we know that the differential reaction to the statement is not activated by respondents' norms.
} 
represented in the national Parliament, including FvD. We use vote intention for FvD to cross-validate our DV, PTV for FvD. This measurement has been validated by work by Van der Eijk et al. (2006) and has been recognized to be well-suited to tap voting behavior.

\section{Moderator: Multiculturalist Attitudes}

These were tapped via asking participants a single question regarding the desirability of immigrants to adapt to Dutch culture: "Do you think that people with a migration background and ethnic minorities living in the Netherlands should adapt to the Dutch culture or that they can hold on to the customs and the traditions of their own culture?" This was assessed on an 11-point scale ranging from a score of 0 ('should fully adapt to the Dutch culture') and a score of 10 ('can hold on to own customs and traditions'). Hence, a higher score means that participants are more supportive of multiculturalism and oppose assimilationism $(M=2.97, S D=2.04)$.

\section{Mediators}

\section{Visibility Forum for Democracy}

The participants were asked: 'Some parties one does not hear from, while other parties are highly visible in public discussions on matters that are relevant in society. How visible was FvD in public debates in the last month?' Responses vary from 1 ("not visible at all") to 7 ("very visible"). $(M=4.12, S D=1.71)$.

\section{Issue Salience of Immigration}

The participants were asked to indicate for a number of key political issues how important they think they are and to what extent these issues would play a role in their vote choice. This was assessed on a 7-point scale ranging from 1 ("not important at all") to 7 ("very important"). They could choose from a close-ended list which included immigration alongside other political issues, such as unemployment. For this variable, we used participants' scores for the immigration issue. A higher score indicates that they perceive immigration as a salient political issue which would play a role in their vote choice $(M=4.87 ; S D=1.52)$.

\section{Perceived Effectiveness}

For perceived party effectiveness, we made use of a scale which has been validated in prior surveys (Van Spanje and Azrout 2019). The scale consisted of a sum score of participants' answers on four items which were all measured on a 7-point scale ranging from 1 ("Not at all") to 7 ("To a high extent"): "To what extent is the organization of FvD stable according to you?'; 'To what extent do you believe that FvD can actually achieve something for those who voted for that party?'; 'To what extent is FvD an efficient organization?'; 'To what extent do you expect FvD to attain 
its goals?' This formed a reliable and unidimensional scale $(\alpha=0.92, M=2.78$; $S D=1.28)$.

\section{Perceived Legitimacy Forum for Democracy (FvD)}

We made use of a scale which has been validated in prior research (Van Spanje and Azrout 2019). More specifically, voters' perceptions of legitimacy were measured via their assessment of four statements on a 7-point Likert scale ranging from 'not at all' (1) to 'to a high extent' (7). These statements were: 'To what extent does FvD comply with the law, do you think?'; 'To what extent do you think FvD has the right to exert power?'; 'To what extent do the leaders of FvD respect the rules of our democracy, do you think?'; 'To what extent do you think FvD abides by the prevailing social norms in our society?'. Analysis shows that this forms a reliable scale with a high internal consistency $(\alpha=0.92, M=3.51 S D=1.48)$.

\section{Anti-establishment Attitudes}

This was measured via participants' assessments of three statements using 7-point scale from 1 ('Completely disagree') to 7 ('Completely agree'). The three statements were: 'The people instead of politicians should make our most important policy decisions'; 'Politicians in government are corrupt'; 'Politicians make decisions that harm the interest of the ordinary people'. These items have been based upon prior studies, and have been slightly adapted by reducing the number of items (Hameleers et al. 2017; Rooduijn 2014). Higher scores correspond to higher antiestablishment attitudes. The scale proved to be internally consistent and reliable $(\alpha=0.85, M=3.78, S D=1.59)$.

\section{Support for Freedom of Speech}

To measure support for freedom of speech we relied on a scale used by the PEW Research Center. Participants were asked to rate three statements on a 7-point scale from 1 ('the government should forbid people to make these comments') to 7 ('people should be free to make these comments in public'): 'statements calling for violent protests'; 'comments that are insulting toward one's religion or religious beliefs', 'comments that are insulting toward ethnic minority groups.' A higher score means higher support for freedom of speech $(\alpha=0.78, M=3.02, S D=1.35)$.

\section{Analysis}

A linear regression analysis was conducted to assess whether participants between the control and experimental condition differ in their PTV for FvD and to examine whether multiculturalism attitudes moderate this relationship $\left(\mathrm{H}_{1}\right)$. For $\mathrm{H}_{2}$ to $\mathrm{H}_{7}$, we made use of the PROCESS Macro in SPSS 24 (Hayes 2013), because this package allows us to test mediated moderation models with Model 8 in a straightforward 
Table 1 Manipulation checks for experimental condition

\begin{tabular}{llll}
\hline Manipulation & $\mathrm{N}$ in condition & $\mathrm{N}$ correct & \% Correct \\
\hline Decision to prosecute & 181 & 118 & 65.2 \\
Theo Hiddema & 181 & 154 & 85.1 \\
\hline
\end{tabular}

way. ${ }^{9}$ However, we have also tested separate linear regressions. Missing data were imputed via the multiple imputation option in SPSS. ${ }^{10}$

\section{Results}

\section{Randomization and Manipulation Check}

A randomization check ascertains that no significant differences between the experimental and control condition were present in terms of gender $[F(1,369)=1.200$, $p=0.255]$, age $[F(1,369)=0.026, p=0.872]$, education $[F(1,369)=0.446$, $p=0.504]$, political interest $[F(1,369)=0.003, p=0.956]$, party identification $[F(1$, $369)=0.269, p=0.604]$, and political ideology $[F(1,369)=0.863, p=0.353]$. The randomization was successful. Next, we checked whether the stimuli in the experimental condition were effective. This was done in two ways. First, participants were asked which politician they saw in the news story. This was administered with a multiple-choice question; the answering options included Hiddema, three other national politicians from another party and 'don't know' option. Second, participants were asked about the main message of the news story. They had to select which scenario best described what they had seen: 'Hiddema will be prosecuted for statements about Muslims'; 'Hiddema will not be prosecuted for statements about Muslims'; 'Hiddema made statements about Muslims, but no information about prosecution was given', 'Don't know'. Results (see Table 1) indicate that most participants correctly perceived the manipulation. We conducted our analyses with and without inclusion of the participants who correctly perceived the manipulation, which resulted in the same conclusions. ${ }^{11}$

\footnotetext{
9 This is a specific type of model in the Hayes Process Macro to be used for a moderated mediation where both mediators and moderators are being modelled and where we can include a moderator while estimating the relationship between the IVs and the mediator as well as a moderator while estimating the relationship between the mediator and the DV.

${ }^{10}$ Running the analyses with and without imputed missing values led to the same conclusions. We opted to report the result with multiple imputation as this maximizes test power. These results are available from the authors upon request.

11 This qualifies concerns regarding Intention-to-Treat (ITT) effects. Results from this analysis are available from the authors upon request.
} 
Table 2 Linear regression analysis on propensity to vote for FvD

\begin{tabular}{|c|c|c|c|c|c|c|}
\hline \multirow[t]{2}{*}{ DV: propensity to vote for FvD } & \multicolumn{3}{|l|}{ Model I } & \multicolumn{3}{|l|}{ Model II } \\
\hline & B (SE) & $\beta$ & $p$ & B (SE) & $\beta$ & $p$ \\
\hline Constant & $3.69(0.27)^{* *}$ & & 0.003 & $1.88(0.82)^{*}$ & & 0.023 \\
\hline News hate speech prosecution & $-0.16(0.28)$ & -0.03 & 0.557 & $-0.05(0.49)$ & -0.01 & 0.920 \\
\hline Multiculturalist attitude & $-0.18(0.07)^{* * *}$ & -0.14 & 0.000 & $-0.16(0.10)$ & -0.12 & 0.109 \\
\hline Interaction & & & & $-0.04(0.14)$ & -0.03 & 0.780 \\
\hline $\mathrm{R}^{2}$ & 0.015 & & & & 0.012 & \\
\hline $\mathrm{N}$ & 372 & & & & 372 & \\
\hline
\end{tabular}

Reported are the unstandardized coefficients (B), standard errors (SEs), standardized coefficients $(\beta)$ and significance values $(p)$

$* * * p<0.001, * * p<0.01, * p<0.05$

\section{Main Effect}

Univariate analysis of variance (ANOVA) was conducted to examine any main effect of exposure to a news story about prosecution on the PTV for FvD. We do not expect a main effect, as we expect that participants' reaction will be moderated by multiculturalist attitudes $\left(\mathrm{H}_{1}\right)$. Our analysis indeed finds no significant main effect of exposure to news about hate speech prosecution, $F(1,369)=0.378$, $p=0.539, \eta_{p}^{2}=0.001$. Participants in the experimental condition $(\mathrm{M}=2.99$, $\mathrm{SD}=2.58,95 \%$ CI $[2.61,3.37])$ do not significantly differ in their PTV FvD compared to those in the control condition $(\mathrm{M}=3.16, \mathrm{SD}=2.75,95 \%$ CI [2.77, $3.56])$.

\section{Moderation}

Next, we test $\mathrm{H}_{1}$, which states that exposure to a news story about hate speech prosecution of an anti-immigration party leader will have differential effects for voters high and low in multiculturalist attitudes. More specifically, we anticipate a positive effect of hate speech prosecution on anti-immigration party support amongst voters that are low in multiculturalist attitudes. A linear regression analysis was conducted with PTV for FvD as DV, and exposure to a television news story on hate speech prosecution and multiculturalist attitudes as IVs (Model I). We also test the interaction between both IVs (Model II). Results displayed in Table 2 indicate that while being low in multiculturalist attitudes (Model 1) is positively correlated with PTV for FvD, the interaction term (Model II) between exposure to a news story about hate speech prosecution and multiculturalist attitudes is not significant. Figure 2 shows that exposure to a news story about hate speech prosecution decreases PTV for FvD for voters who are high and low in multiculturalist attitudes, but that the decrease is slightly stronger (but not statistically significant) for voters high in multiculturalist attitudes. We reject $\mathrm{H}_{1}$. 


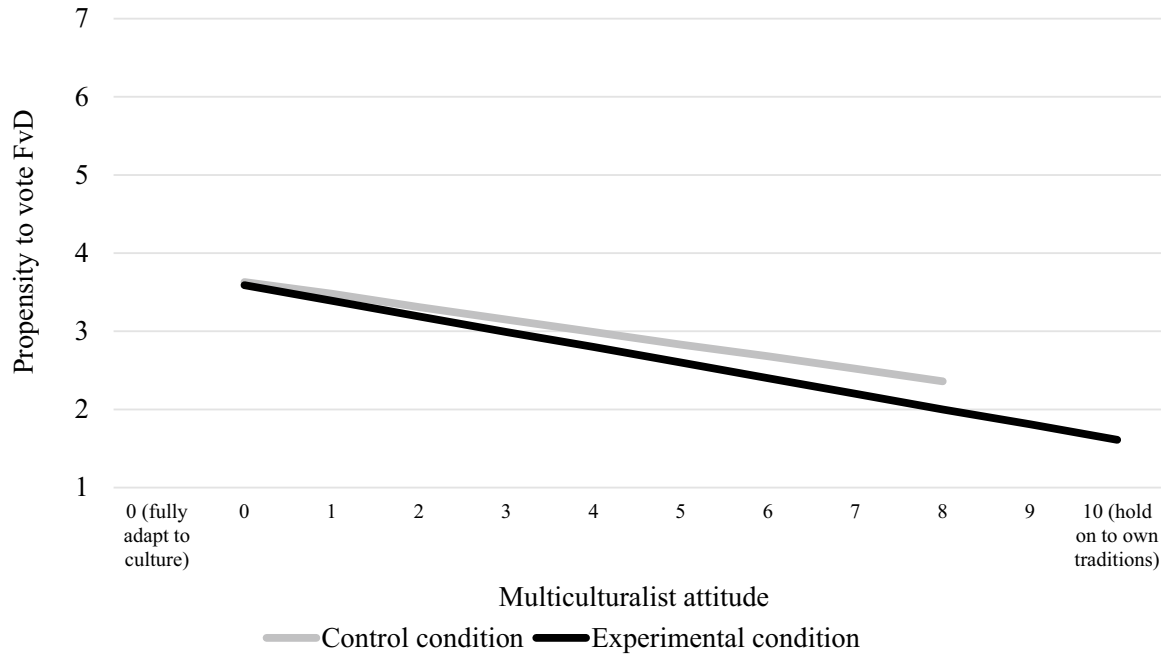

Fig. 2 Interaction effect on propensity to vote for FvD

\section{Mediators}

Finally, to assess to what extent the relationship between exposure to a news story about hate speech prosecution and PTV for FvD is mediated $\left(\mathrm{H}_{2}\right.$ to $\left.\mathrm{H}_{7}\right)$, we used the PROCESS Macro (Hayes 2013). We fitted six mediated moderation regression models (Model 8) with 5000 bootstrap samples, one for each mediator, with multiculturalist attitudes as moderator. We also fitted separate regression models per mediator to obtain standardized regression coefficients. Full findings are reported in Table 3; below, only the significant results are discussed.

We first examine the effects of exposure to a news story about hate speech prosecution, multiculturalist attitudes and their interaction on the mediators. Findings show that visibility of FvD and support for free speech are affected by the interaction between exposure to the stimulus and multiculturalist attitude. Voters who support multiculturalism perceive FvD to be more visible after exposure to a news story about hate speech prosecution; moreover, the same type of voter is also more likely to support freedom of speech after such exposure. The effect of the stimulus on voters who are low in multiculturalist attitudes is reversed. It should be noted, however, that these effects are rather modest in size, as the standardized coefficient ranges from 0.20 to 0.30 . No significant results are found on the other mediators. Figures 3 and 4 offer a visual illustration of the interaction.

In a next step, we assess whether the mediators affect PTV for FvD. This is the case for all mediators. Higher perceived efficacy, higher perceived legitimacy, anti-establishment attitudes and perceiving immigration as a key political issue all result in higher PTV for FvD. Higher perceived visibility of FvD and support for free speech are also positively correlated with FvD support. We can thus conclude that exposure to a news story about hate speech prosecution boosts support about free speech and renders FvD more visible, which are elements conducive 
Table 3 Hypothesized relations between exposure to news story about hate speech prosecution, mediators and the propensity to vote for FvD

\begin{tabular}{|c|c|c|c|c|c|c|}
\hline & & & B & SE & $\beta$ & $p$ \\
\hline \multicolumn{7}{|l|}{ Effects on mediators } \\
\hline \multirow[t]{3}{*}{ Visibility of FvD } & $\leftarrow$ & $\begin{array}{l}\text { News story hate speech pros- } \\
\text { ecution }\end{array}$ & -0.44 & 0.31 & -0.13 & 0.167 \\
\hline & $\leftarrow$ & Multiculturalist attitudes & $-0.16^{*}$ & 0.06 & -0.19 & 0.012 \\
\hline & $\leftarrow$ & Interaction & $0.21 *$ & 0.09 & 0.26 & 0.017 \\
\hline \multirow[t]{3}{*}{ Issue salience of immigration } & $\leftarrow$ & $\begin{array}{l}\text { News story hate speech pros- } \\
\text { ecution }\end{array}$ & 0.02 & 0.28 & 0.01 & 0.942 \\
\hline & $\leftarrow$ & Multiculturalist attitudes & $-0.14 *$ & 0.06 & -0.18 & 0.018 \\
\hline & $\leftarrow$ & Interaction & 0.06 & 0.07 & 0.09 & 0.390 \\
\hline \multirow[t]{3}{*}{ Perceived effectiveness } & $\leftarrow$ & $\begin{array}{l}\text { News story hate speech pros- } \\
\text { ecution }\end{array}$ & -0.14 & 0.23 & -0.05 & 0.547 \\
\hline & $\leftarrow$ & Multiculturalist attitudes & $-0.12 * *$ & 0.05 & -0.20 & 0.009 \\
\hline & $\leftarrow$ & Interaction & 0.02 & 0.06 & 0.04 & 0.709 \\
\hline \multirow[t]{3}{*}{ Perceived legitimacy } & $\leftarrow$ & $\begin{array}{l}\text { News story hate speech pros- } \\
\text { ecution }\end{array}$ & 0.02 & 0.27 & 0.01 & 0.944 \\
\hline & $\leftarrow$ & Multiculturalist attitudes & $-0.14^{*}$ & 0.06 & -0.19 & 0.011 \\
\hline & $\leftarrow$ & Interaction & 0.00 & 0.08 & 0.00 & 0.991 \\
\hline \multirow[t]{3}{*}{ Support for free speech } & $\leftarrow$ & $\begin{array}{l}\text { News story hate speech pros- } \\
\text { ecution }\end{array}$ & $-0.76^{* *}$ & 0.25 & -0.28 & 0.002 \\
\hline & $\leftarrow$ & Multiculturalist attitudes & $-0.18^{* * *}$ & 0.05 & -0.27 & 0.000 \\
\hline & $\leftarrow$ & Interaction & $0.19 * *$ & 0.07 & 0.30 & 0.005 \\
\hline \multirow[t]{3}{*}{ Anti-establishment attitudes } & $\leftarrow$ & $\begin{array}{l}\text { News story hate speech pros- } \\
\text { ecution }\end{array}$ & -0.38 & 0.28 & -0.12 & 0.179 \\
\hline & $\leftarrow$ & Multiculturalist attitudes & $-0.29 * * *$ & 0.06 & -0.37 & 0.000 \\
\hline & $\leftarrow$ & Interaction & 0.13 & 0.08 & 0.17 & 0.102 \\
\hline \multicolumn{7}{|l|}{ Effects of mediators on DV } \\
\hline \multirow[t]{4}{*}{ Propensity to vote for FvD } & $\leftarrow$ & Visibility of FvD & $0.34 * * *$ & 0.08 & 0.22 & 0.000 \\
\hline & $\leftarrow$ & Multiculturalist attitudes & -0.10 & 0.09 & -0.08 & 0.288 \\
\hline & $\leftarrow$ & $\begin{array}{l}\text { News story hate speech pros- } \\
\text { ecution }\end{array}$ & 0.10 & 0.48 & 0.02 & 0.834 \\
\hline & $\leftarrow$ & Interaction & -0.11 & 0.13 & -0.09 & 0.412 \\
\hline \multirow[t]{4}{*}{ Propensity to vote for FvD } & $\leftarrow$ & Issue salience of immigration & $0.42 * * *$ & 0.09 & 0.24 & 0.000 \\
\hline & $\leftarrow$ & Multiculturalist attitudes & -0.10 & 0.09 & -0.08 & 0.291 \\
\hline & $\leftarrow$ & $\begin{array}{l}\text { News story hate speech pros- } \\
\text { ecution }\end{array}$ & -0.06 & 0.48 & -0.01 & 0.904 \\
\hline & $\leftarrow$ & Interaction & -0.07 & 0.13 & -0.05 & 0.618 \\
\hline \multirow[t]{4}{*}{ Propensity to vote for FvD } & $\leftarrow$ & Perceived effectiveness FvD & $1.06^{* * * *}$ & 0.10 & 0.51 & 0.000 \\
\hline & $\leftarrow$ & Multiculturalist attitudes & -0.03 & 0.09 & -0.02 & 0.742 \\
\hline & $\leftarrow$ & $\begin{array}{l}\text { News story hate speech pros- } \\
\text { ecution }\end{array}$ & 0.10 & 0.42 & 0.02 & 0.814 \\
\hline & $\leftarrow$ & Interaction & -0.06 & 0.12 & -0.05 & 0.589 \\
\hline \multirow[t]{2}{*}{ Propensity to vote for FvD } & $\leftarrow$ & Perceived legitimacy FvD & $0.99 * * *$ & 0.08 & 0.55 & 0.000 \\
\hline & $\leftarrow$ & Multiculturalist attitudes & -0.02 & 0.08 & -0.02 & 0.802 \\
\hline
\end{tabular}


Table 3 (continued)

\begin{tabular}{|c|c|c|c|c|c|c|}
\hline & & & B & SE & $\beta$ & $p$ \\
\hline & $\leftarrow$ & $\begin{array}{l}\text { News story hate speech pros- } \\
\text { ecution }\end{array}$ & -0.07 & 0.41 & -0.01 & 0.869 \\
\hline & $\leftarrow$ & Interaction & -0.04 & 0.11 & -0.03 & 0.734 \\
\hline \multirow[t]{4}{*}{ Propensity to vote for FvD } & $\leftarrow$ & Support for free speech & $0.40 * * *$ & 0.10 & 0.20 & 0.000 \\
\hline & $\leftarrow$ & Multiculturalist attitudes & -0.09 & 0.09 & -0.07 & 0.380 \\
\hline & $\leftarrow$ & $\begin{array}{l}\text { News story hate speech pros- } \\
\text { ecution }\end{array}$ & 0.26 & 0.49 & 0.05 & 0.599 \\
\hline & $\leftarrow$ & Interaction & -0.12 & 0.13 & -0.09 & 0.394 \\
\hline \multirow[t]{4}{*}{ Propensity to vote for FvD } & $\leftarrow$ & Anti-establishment attitudes & $0.42 * * *$ & 0.09 & 0.25 & 0.000 \\
\hline & $\leftarrow$ & Multiculturalist attitudes & -0.04 & 0.10 & -0.03 & 0.681 \\
\hline & $\leftarrow$ & $\begin{array}{l}\text { News story hate speech pros- } \\
\text { ecution }\end{array}$ & 0.11 & 0.48 & 0.02 & 0.819 \\
\hline & $\leftarrow$ & Interaction & -0.13 & 0.08 & -0.07 & 0.491 \\
\hline
\end{tabular}

Entries are the result of mediated moderation analysis in SPSS 24 using the Hayes PROCESS Macro. Reported are the unstandardized coefficients $(B)$, standard errors (SEs), standardized coefficients $(\beta)$ and significance values $(p)$

$* * * p<0.001, * * p<0.01, * p<0.05$

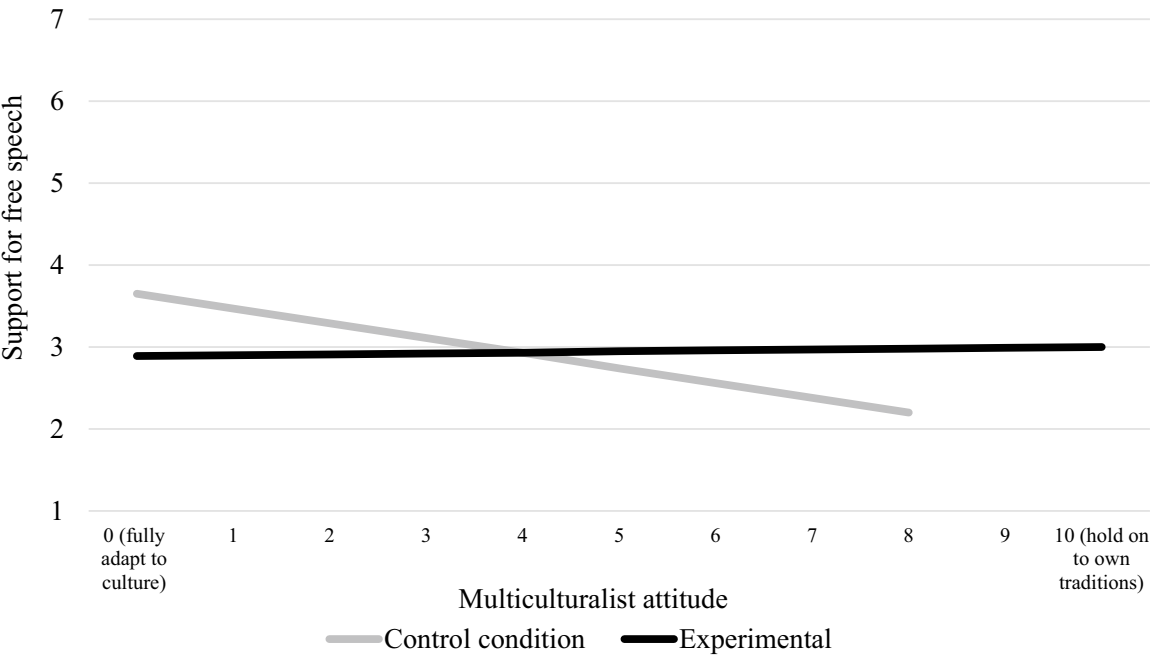

Fig. 3 Interaction effect on support for free speech

to FvD support. This effect holds for voters with positive views on multiculturalism. Thus, we do not find uniform support for a mediation effect, and none of the hypotheses are confirmed, as the effect on perceived FvD visibility and free speech only holds for those who are supportive of multiculturalism. We have also tested whether these effects are robust via assessing whether both effects 


\section{Discussion}

In this study, we examine how news regarding hate speech prosecution affects levels of electoral support. We go beyond prior studies via disentangling the mechanisms that may be at play after voters' exposure to news regarding prosecution. We empirically test six potential explanations based upon literature on political communication and electoral behavior: priming and issue ownership theory, perceived effectiveness and legitimacy, support for free speech and anti-establishment attitudes. We design an experiment in which participants are exposed to a news story about hate speech prosecution of Theo Hiddema, an MP of the Dutch FvD.

Overall, findings are layered. First, they indicate that exposure to a news story about hate speech prosecution yields no main effect. Hence, exposure to hate speech prosecution does not directly boost the PTV for FvD. Second, the hypothesized interaction effect that exposure to a news story about hate speech prosecution would only boost support amongst participants that are low in multiculturalist attitudes was not confirmed either. What we did find was that exposure to a news story about hate speech prosecution has an effect on both support for free speech and perceived visibility of FvD amongst those participants that are high in multiculturalist attitudes. Below, we discuss both findings in greater detail.

First, voters who support multiculturalism perceive FvD as more visible in the public debate after exposure; visibility, in turn, is positively correlated with the PTV for $\mathrm{FvD}$; this latter pattern can be seen as a confirmation of priming theory (Weaver 2007), where voters apply news about a particular issue regarding FvD (in this case prosecution for hate speech) when evaluating that party. No such effect occurred when voters were exposed to a news story regarding general hate speech (statements about Muslims) without referring to prosecution. The mentioning of prosecution may add extra conflict value to the news story, which could increase its salience (Aalberg et al. 2012) and which may explain why it is applied in subsequent judgments. Prosecution is a controversial decision, and it is a new element compared to statements about Muslims, which is a recurring aspect of anti-immigration parties' discourse.

Second, a similar mechanism is observed for support for free speech: exposure to a news story regarding hate speech prosecution enhances support for free speech amongst voters who support multiculturalism; support for free speech, in turn, is positively correlated with the PTV for FvD. Possibly, voters with a multiculturalist orientation-even though they do not sympathize with the ideas as propagated by an anti-immigration party - may feel that freedom of speech is at stake in the context of prosecution, which may have an indirect effect on electoral support. Free speech is of course also a core liberal right, which may pose a dilemma to these voters. In this regard, our results are generally in line with Lahav and Courtemanche (2012), who find that conservatives may attract support from across the aisle by framing immigration issues in particular ways.

The finding that these mechanisms are at work for voters who are positive toward multicultural society implies that hate speech prosecution can have unintended consequences via activating attitudes and voter perceptions that are favorable for the 
party of the prosecuted politician amongst this group. However, there is no clear evidence for a backlash effect of hate speech prosecution amongst anti-immigration voters. Similarly, one should not overestimate these effects, as we do not find evidence of an actual mediation effect. We merely observe that exposure to a news story about hate speech prosecution increases support for free speech and perceived visibility of FvD for participants who favor multiculturalism, and these aspects are found to be positively correlated with the PTV for FvD. Moreover, the effects are rather modest in magnitude.

Two significant null findings in our study warrant more reflection: there is no significant main effect of exposure to a news story about hate speech prosecution. Importantly, there is no interaction effect between exposure to a news story about hate speech prosecution and multiculturalist attitudes on the PTV FvD. This result diverges from the finding by Van Spanje and De Vreese (2015) that especially voters with moderate assimilationist attitudes were more inclined to vote PVV when confronted with prosecution. These differences may be due to the distinct party image of FvD when compared to PVV: it is a smaller and newer party about which many voters do not have much information yet, and which is less outspoken about its opposition to multiculturalism than PVV is; this, could, however, also result in larger effects. Hence, one could also conclude from the results of our experiment that overall hate speech prosecution does not have far-reaching consequences when it comes to people's PTV for an anti-immigration party, except that it renders a party more salient and boosts other attitudes that are subsequently found to predict support for that party. It should be noted that the Dutch public has also been confronted with two trials for hate speech in the past, which could make that they to some extent have already become used to news about hate speech prosecution. Still, while only significant effects were found on perceived party salience and support for free speech, we also observe a trend for anti-establishment attitudes: voters with an assimilationist attitude had higher anti-establishment attitudes after exposure to a news story about hate speech prosecution, while voters with a multiculturalist attitude report lower anti-establishment attitudes after exposure to a news story about prosecution.

This study has shortcomings that should be acknowledged. First, the study does not consider divergences in the way hate speech prosecution is framed in the news. Framing patterns may condition how people respond to it: news may for instance frame hate speech prosecution as a way to curb racism, or as a political trial or an attack on free speech and these frames are expected to yield different effects. Future research should more closely study framing effects. Second, we make use of an existing party that is newly founded within the Dutch context; to some extent this may have affected our results and may explain why our results are not fully in line with prior studies focusing on other parties. Therefore, replication is needed to assess whether results can be generalized to other contexts and parties. Finally, the experiment only tests respondents' attitudes at one point in time; the duration of media effects warrants close examination in the future. Priming and issue ownership may take some time before and will arguably not be strongly affected by exposure to one news story. Still, it should be noted that trials for hate speech tend to be highly 
mediatized (Jacobs and van Spanje 2018), making that repetitive exposure to the same type of content is rather likely.

In sum, however, our conclusion on the basis of our experiment is that the electoral ramifications of exposure to a news story about the hate speech prosecution of a politician work rather subtly: in the context of a newly founded anti-immigration party, exposure to a news story about hate speech prosecution increases support for free speech and the perceived visibility of that party amongst voters who are positive toward multiculturalism. Both aspects are positively correlated with voting for FvD. However, no main effect was found; nor did voters who are low in multiculturalist attitudes become more inclined to vote for FvD. For now, it seems that legal prosecution of anti-immigration party actors has subtle effects by activating attitudes that are beneficial for anti-immigration party support, but this mechanism warrants future in-depth investigation.

Acknowledgements We would like to thank Lisanne Wichgers for her valuable assistance with the data collection.

Funding This work was supported by the Netherlands Organisation for Scientific Research (NWO) with a VIDI Grant of Dr. Joost van Spanje (Project Number 452-14-002).

Open Access This article is distributed under the terms of the Creative Commons Attribution 4.0 International License (http://creativecommons.org/licenses/by/4.0/), which permits unrestricted use, distribution, and reproduction in any medium, provided you give appropriate credit to the original author(s) and the source, provide a link to the Creative Commons license, and indicate if changes were made.

\section{References}

Aalberg, T., Strömbäck, J., \& De Vreese, C. H. (2012). The framing of politics as strategy and game: A review of concepts, operationalizations and key findings. Journalism, 13(2), 162-178.

Akkerman, T. (2005). Anti-immigration parties and the defence of liberal values: The exceptional case of the List Pim Fortuyn. Journal of Political Ideologies, 10(3), 337-354.

Akkerman, T. (2011). Friend or foe? Right-wing populism and the popular press in Britain and the Netherlands. Journalism: Theory, Practice and Criticism, 12(8), 931-945.

Barkan, S. E. (2006). Criminal prosecution and the legal control of protest. Mobilization, 11(2), 181-194.

Bélanger, É., \& Meguid, B. M. (2008). Issue salience, issue ownership, and issue-based vote choice. Electoral Studies, 27(3), 477-491.

Belknap, M. R. (1994). Introduction: Political trials in the American past. In M. R. Belknap (Ed.), American political trials. London: Praeger.

Berntzen, L. E., Bjånesøy, L., \& Ivarsflaten, E. (2017). Patterns of legitimacy on the far right. In Paper presented at ECPR general conference, Oslo.

Bleich, E. (2011). The freedom to be racist: How the United States and Europe struggle to preserve freedom and combat racism. Oxford: Oxford University Press.

Blinder, S., Ford, R., \& Ivarsflaten, E. (2013). The better angels of our nature: How the antiprejudice norm affects policy and party preferences in Great Britain and Germany. American Journal of Political Science, 57(4), 841-857.

Bos, L., Lefevere, J. M., Thijssen, R., \& Sheets, P. (2017). The impact of mediated party issue strategies on electoral support. Party Politics, 23(6), 760-771.

Bos, L., \& Van der Brug, W. (2010). Public images of leaders of anti-immigration parties: Perceptions of legitimacy and effectiveness. Party Politics, 16(6), 777-799. 
Burscher, B., Van Spanje, J., \& De Vreese, C. H. (2015). Owning the issues of crime and immigration: The relation between immigration and crime news and anti-immigrant voting in 11 countries. Electoral Studies, 38, 59-69.

Capoccia, G. (2005). Defending democracy: Reactions to extremism in interwar Europe. London: Johns Hopkins University Press.

Capoccia, G. (2013). Militant democracy: The institutional bases of democratic self-preservation. Annual Review of Law and Social Science, 9(1), 207-226.

Carter, E. (2005). The extreme right in Western Europe: Success or failure?. Manchester: Manchester University Press.

Cutts, D., Ford, R., \& Goodwin, M. J. (2011). Anti-immigrant, politically disaffected or still racist after all? Examining the attitudinal drivers of extreme right support in Britain in the 2009 European elections. European Journal of Political Research, 50(3), 418-440.

Damstra, A., Jacobs, L., Boukes, M., \& Vliegenthart, R. (in press). The impact of immigration news on anti-immigrant party support: Unpacking the issue ownership effect over time. Journal of Elections, Public Opinion and Parties.

Downs, A. (1957). An economic theory of democracy. New York: Harper and Row.

Eatwell, R. (2003). Ten theories of the extreme right. In P. Merkl \& L. Weinberg (Eds.), Right-wing extremism in the twenty-first century. London: Frank Cass.

Fennema, M. (1997). Some conceptual issues and problems in the comparison of anti-immigrant parties in Western Europe. Party Politics, 3(4), 473-492.

Fennema, M. (2000). Legal repression of extreme-right parties and racial discrimination. In R. Koopmans \& P. Statham (Eds.), Challenging immigration and ethnic relations politics. Oxford: Oxford University Press.

Friedman, L. (1970). Political power and legal legitimacy: A short history of political trials. The Antioch Review, 30(2), 156-170.

Green, J., \& Hobolt, S. B. (2008). Owning the issue agenda: Party strategies and vote choices in British elections. Electoral Studies, 27(3), 460-476.

Hakman, N. (1972). Political trials in the legal order: A political scientist's perspective. Journal of Public Law, 21, 73-126.

Hameleers, M., Bos, L., \& de Vreese, C. H. (2017). The appeal of media populism: The media preferences of citizens with populist attitudes. Mass Communication and Society, 20(4), 481-504.

Harcup, T., \& O’Neill, D. (2017). What is news? News values revisited (again). Journalism Studies, 18(12), 1470-1488.

Hayes, A. F. (2013). Introduction to mediation, moderation, and conditional Process analysis: A regression-based approach. New York, NY: The Guilford Press. Hillygus.

Hopmann, D. N., Vliegenthart, R., De Vreese, C. H., \& Albaek, E. (2010). Effects of election news coverage: How visibility and tone influence party choice. Political Communication, 27(4), 389-405.

Jacobs, L. \& van Spanje, J. (2018). Prosecuted, but popular? Hate speech prosecution of anti-immigrant politicians in the news and electoral support. In Paper presented at ECPR Joint Sessions, Nicosia.

Jagers, J., \& Walgrave, S. (2007). Populism as political communication style: An empirical study of political parties' discourse in Belgium. European Journal of Political Research, 46(3), 319-345.

Kirchheimer, O. (1961). Political justice. The use of legal procedure for political ends. Princeton, NJ: Princeton University Press.

Kitschelt, H., \& McGann, A. (1995). The radical right in Western Europe: A comparative analysis. Ann Arbor, MI: University of Michigan.

Lahav, G., \& Courtemanche, M. (2012). The ideological effects of framing threat on immigration and civil liberties. Political Behavior, 34, 477-505.

Loewenstein, K. (1937). Militant democracy and fundamental rights, II. American Political Science Review, 31(4), 638-658.

Mendelberg, T. (2001). The race card: Campaign strategy, implicit messages, and the norm of equality. Princeton, NJ: Princeton University Press.

Minkenberg, M. (2006). Repression and reaction: Militant democracy and the radical right in Germany and France. Patterns of Prejudice, 40(1), 25-44.

More, G. (1994). Undercover surveillance of the Republikaner Party: Protecting a militant democracy or discrediting a political rival? German Politics, 3(2), 284-292.

Petrocik, J. (1996). Issue ownership in presidential elections, with a 1980 case study. American Journal of Political Science, 40(3), 825-850. 
Pettigrew, T. F., \& Meertens, R. W. (1995). Subtle and blatant prejudice in Western Europe. European Journal of Social Psychology, 25(1), 57-75.

Posner, E. A. (2014). Political trials in domestic and international law. Duke Law Journal, 55(1), 75-152.

Rooduijn, M. (2014). Vox populismus: A populist radical right attitude among the public? Nations and Nationalism, 20(1), 80-92.

Rooduijn, M., Van der Brug, W., \& De Lange, S. L. (2016). Expressing or fuelling discontent? The relationship between populist voting and political discontent. Electoral Studies, 43(1), 32-40.

Scheufele, D. A., \& Tewksbury, D. (2007). Framing, agenda setting, and priming: The evolution of three media effects models. Journal of Communication, 57(1), 9-20.

Sheafer, T. (2007). How to evaluate it: The role of story-evaluative tone in agenda setting and priming. Journal of Communication, 57(1), 21-39.

Stockemer, D. (2017). The success of radical right-wing parties in Western European regions-New challenging findings. Journal of Contemporary European Studies, 25(1), 41-56.

Thiel, M. (2009). Introduction. In M. Thiel (Ed.), The “Militant Democracy" principle in modern democracies. Farnham: Ashgate.

Van Aelst, P., Maddens, B., Noppe, J., \& Fiers, S. (2008). Politicians in the news: Media or party logic? Media attention and electoral success in the Belgian election campaign of 2003. European Journal of Communication, 23(2), 193-210.

Van der Brug, W. (2004). Issue ownership and party choice. Electoral Studies, 23(2), 209-233.

Van der Brug, W., Fennema, M., \& Tillie, J. (2005). Why some anti-immigrant parties fail and others succeed. A two-step model of aggregate electoral support. Comparative Political Studies. https://doi. org/10.1177/0010414004273928.

Van der Eijk, C., Van der Brug, W., Kroh, M., \& Franklin, M. (2006). Rethinking the dependent variable in voting behavior: On the measurement and analysis of electoral utilities. Electoral Studies, 25(3), 424-47.

Van Donselaar, J. (1995). De staat paraat? De bestrijding van extreem-rechts in West-Europa. The Hague: Babylon-De Geus.

Van Heerden, S. H., \& Van der Brug, W. (2017). Demonisation and electoral support for populist radical right parties: A temporary effect. Electoral Studies, 47(1), 36-45.

Van Spanje, J. (2011). The wrong and the right: A comparative analysis of "anti-immigration" and "far right" parties. Government and Opposition, 46(3), 293-320.

Van Spanje, J., \& Azrout, R. (2019). Tainted love: How stigmatization of a political party in news media reduces its electoral support. International Journal of Public Opinion Research, 31(2), 283-308.

Van Spanje, J., \& De Vreese, C. H. (2015). The good, the bad and the voter: The impact of hate speech prosecution of a politician on electoral support for his party. Party Politics, 21(1), 115-130.

Vliegenthart, R., Boomgaarden, H. G., \& Van Spanje, J. (2012). Anti-immigrant party support and media visibility: A cross-party, over-time perspective. Journal of Elections, Public Opinion and Parties, 22(3), 315-358.

Vrielink, J. (2010). Van haat gesproken? Een rechtsantropologisch onderzoek naar de bestrijding van rasgerelateerde uitingsdelicten in Belgie. Antwerpen: Maklu.

Vrielink, J. (2016). Do we want more or fewer prosecutions of opinions: The Geert Wilders trial 2.0. Netherlands Journal of Legal Philosophy, 45(2), 2-11.

Walgrave, S., \& De Swert, K. (2004). The making of the (issues of the) Vlaams Blok. Political Communication, 21(4), 479-500.

Walgrave, S., Lefevere, J., \& Tresch, A. (2012). The associative dimension of issue ownership. The Public Opinion Quarterly, 76(4), 771-782.

Weaver, D. H. (2007). Thoughts on agenda setting, framing, and priming. Journal of Communication, $57(1), 142-147$

Weber, A. (2009). Manual on hate speech. Strasbourg: Council of Europe Publishing.

Publisher's Note Springer Nature remains neutral with regard to jurisdictional claims in published maps and institutional affiliations. 